\section{Kohl's Aims for Energy Savings in Warm-Humid Climates}

Kohl's Department Stores partnered with the U.S. Department of Energy (DOE) to develop and implement solutions to build new stores that consume at least $50 \%$ less than the requirements set by ASHRAE/ANSI/IESNA Standard 90.1-2004' as part of DOE's Commercial Building Partnership (CBP) program. ${ }^{2}$ The National Renewable Energy Laboratory (NREL) provided technical expertise on the project.

The first Kohl's store opened in 1962. Since then, the company has expanded to more than 1,100 stores across the country totaling 104 million $\mathrm{ft}^{2}$. Kohl's has a long history of improving energy efficiency in new and existing stores. The design team assesses savings from energy efficiency measures (EEMs) using energy modeling, tests technologies in the field, and widely deploys successful technologies. NREL used EnergyPlus software ${ }^{4}$ to model the company's 55,000- $\mathrm{ft}^{2}$ prototype design using climate data from Myrtle Beach, South Carolina. The prototype design refers to a standard set of store plans that can be tailored to local conditions. NREL also calculated energy savings from new EEMs, starting with the DOE Advanced Energy Design Guide recommendations ${ }^{5}$ to help Kohl's build the business case for new technologies.

Through improvements in the building envelope, HVAC system, and lighting, the current prototype design is expected to save $50 \%$ versus ASHRAE 90.1-2004 and provide the same level of lighting and comfort to customers. Expected energy savings by end use are shown in the graph below. New technologies such as desiccant dehumidification as part of a dedicated outdoor air system and decreasing the store's heating supply air temperature could raise savings to $56 \%$ and appear to be cost effective; they will be considered for future projects. Measured results will not be available for this project because it is scheduled to be built after the end of CBP.

\section{Expected Energy Savings}

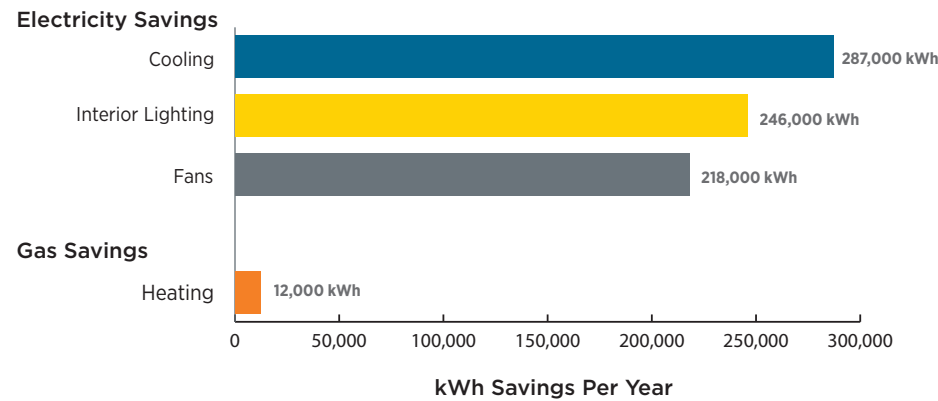

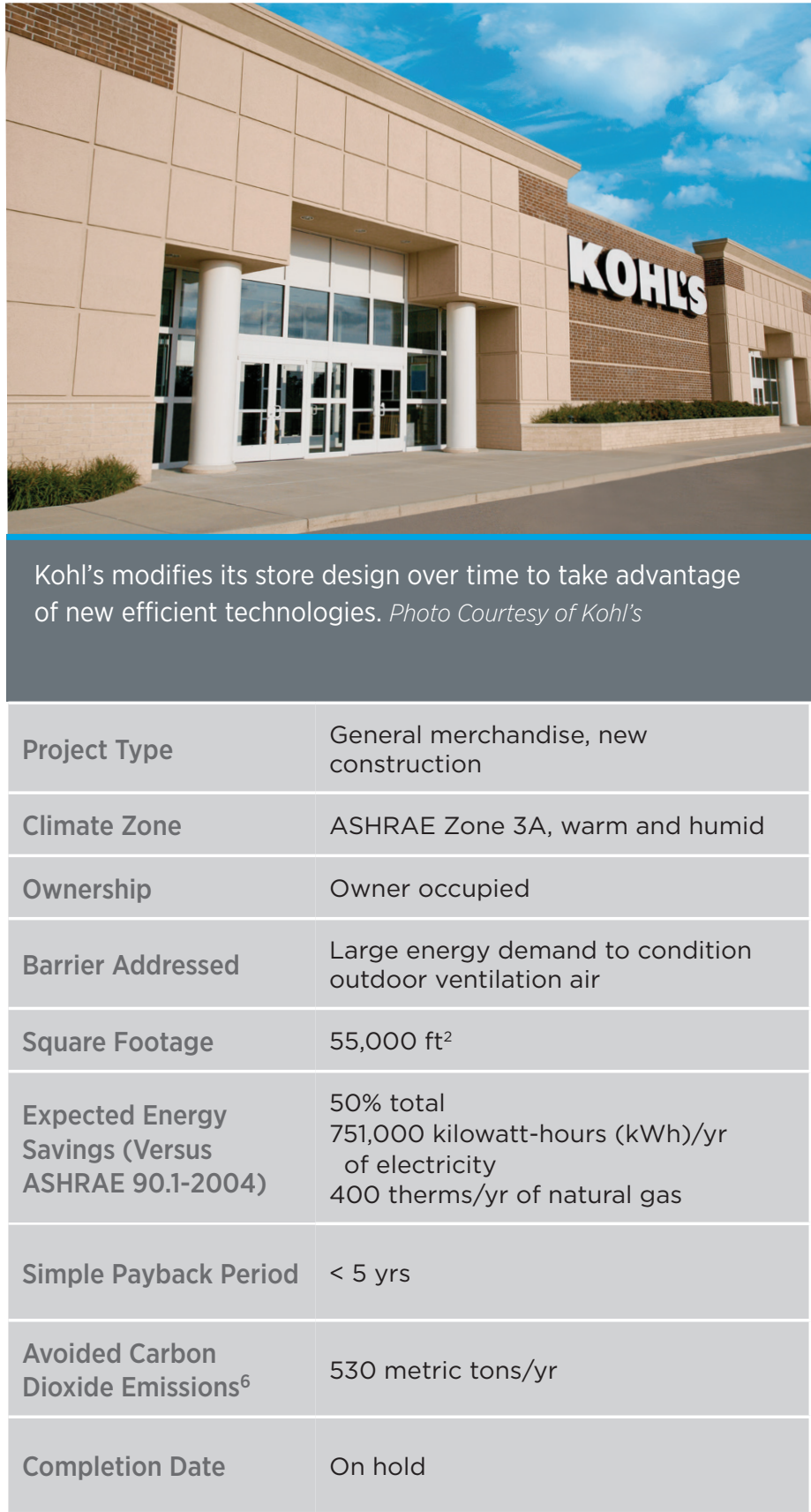

ASHRAE 90.1: https://www.ashrae.org/resources--publications/bookstore/standard90-1-document-history\#2004

CBP is a public/private, cost-shared initiative that demonstrates cost-effective, replicable ways to achieve dramatic energy savings in commercial buildings. Companies and organizations, selected through a competitive process, team with DOE and national laboratory staff who provide technical expertise to explore energy-saving ideas and strategies that are applied to specific building projects and that can be replicated across the market.

DOE Better Buildings Challenge: http://www4.eere.energy.gov/challenge/home

${ }^{4}$ EnergyPlus: http://apps1.eere.energy.gov/buildings/energyplus/

Available through the Commercial Buildings Resource Database: http://buildingdata.

energy.gov/cbrd/

${ }^{6}$ EPA Greenhouse Gas Equivalencies Calculator:

http://www.epa.gov/cleanenergy/energy-resources/calculator.html 


\section{Decision Criteria}

The EEMs for the new construction project needed to satisfy the same criteria as any investment of capital to meet Kohl's obligation to its shareholders. Customer experience was also a primary consideration; any EEM that potentially impacted that experience was closely reviewed from branding and merchandising perspectives. The Kohl's energy team decided to focus on warm, humid climates based on an analysis of their stores' ENERGY STAR ${ }^{\circledR}$ scores, which were lower there compared to other areas of the country.

\section{Economic}

When modifying the Kohl's prototype design, EEMs are judged based on their life cycle costs using a threshold that varies depending on the lifetime of the equipment in question, taking into account utility rebates, climate, capital costs, installation costs, operations and maintenance (O\&M) costs, and energy costs, but not tax incentives. Other details include:

- Although a relatively short payback period is deemed desirable, it is not the sole driving factor in decision-making.

- Kohl's pursues utility rebates where they are available, working with a third party that specializes in identifying and capturing rebate opportunities for its clients.

CBP used ASHRAE 90.1-2004 as the baseline for quantifying savings, but companies like Kohl's are more likely to use the performance of their current prototype design as the reference point for making changes. The prototype design often performs much better than minimum code compliance because of years of continuous improvements, so it becomes more challenging to justify modifying the prototype design, especially for new construction. Sales floor lighting is a good example. Going to $0.63 \mathrm{~W} / \mathrm{ft}^{2}$ installed lighting power density with light emitting diodes must be compared with the prototype fluorescent lighting $\left(0.7 \mathrm{~W} / \mathrm{ft}^{2}\right)$ as opposed to the code minimum $\left(1.5 \mathrm{~W} / \mathrm{ft}^{2}\right)$ when building the business case.

\section{Branding}

Maintaining a consistent look and feel on the sales floor across its stores was a high priority for Kohl's. Kohl's uses a drop (suspended) ceiling with recessed fluorescent lights on a regular grid, giving a uniform feeling. Changes to the lighting system or any prospective daylighting technologies had to take this into account, regardless of the technical implementation challenges. This consideration was a major factor when deciding whether to install LEDs on the sales floor.

\section{Operational}

Kohl's used full life cycle costing to evaluate energy-saving technologies. As a result, technologies with low maintenance costs were judged more favorably than they would be otherwise. For example, LEDs have lower maintenance costs because of their long lifetimes. Demand controlled ventilation was relatively easy and inexpensive to implement and reduced the heating and cooling loads placed on HVAC equipment.

\section{Policy}

Kohl's aims to be a leading environmentally responsible retailer with strategies including sustainable operations, stakeholder engagement, and supply chain collaboration. The company maintains a website, www.kohlsgreen.com, that is dedicated to sharing its sustainability activities with the public and stakeholders.

Achieving the ENERGY STAR ${ }^{\circledR}$ certification for its stores is a major policy driver for Kohl's energy-saving investments. More than 800 of the company's 1,158 stores earned the certification, meaning their energy performance was in the top $25 \%$ of comparable retail stores nationwide. The company earned ENERGY STAR $®$ Sustained Excellence Awards in 2012 and 2013. The company also joined the DOE Better Buildings Challenge, which aims to cut energy use by $20 \%$ company-wide by 2020 , relative to a 2008 baseline. On the supply side, Kohl's has deployed solar panels on more than 140 stores in 12 states using third-party power purchase agreements, with an installed capacity of more than 45 megawatts.

\section{Energy Efficiency Measures}

The table on page 3 shows the expected energy savings of each EEM in the Kohl's prototype design for hot and humid regions and for several additional EEMs under consideration. Wholebuilding savings numbers for each building system include only the EEMs included in the Kohl's new construction prototype and have been calculated relative to the whole building annual energy consumption of the minimally code compliant ASHRAE 90.1-2004 energy model. The business case and energy cost reductions from EEMs are not presented because Kohl's considers equipment capital costs and dollar savings confidential. EEMs that are not applicable in all climates are marked with an asterisk (*). Climate-dependent EEMs should be evaluated to make sure they are a good match for the project location. 


\section{Energy Efficiency Measures}

\section{Building Envelope: 11\% Whole-Building Savings Expected Versus ASHRAE 90.1-2004}

*Increase wall insulation to R-11.5 and roof insulation to R-24.3 versus baseline values of R-8.3 and R-15.9, respectively.

${ }^{*}$ Reflective white roof membrane

\section{Yes}

Yes

\section{Lighting: 23\% Whole-Building Savings Expected Versus ASHRAE 90.1-2004}

Sales floor ambient lighting with fluorescent $2 \times 4$ troffers consuming $0.7 \mathrm{~W} / \mathrm{ft}^{2}$.

Sales floor ambient lighting with LED fixtures consuming $0.63 \mathrm{~W} / \mathrm{ft}^{2}$.

Daylight harvesting with 3\% skylight coverage and continuous electrical light dimming

Use high efficiency LED fixtures for exterior lighting.

\section{HVAC: 34\% Whole-Building Savings Expected Versus ASHRAE 90.1-2004}

High energy efficiency ratio packaged HVAC rooftop units containing variable-speed supply fans and staged heating and cooling

Use demand controlled ventilation controlled by store carbon dioxide concentration.

$85^{\circ} \mathrm{F}$ heating supply air temperature.

${ }^{*}$ Desiccant dehumidification using a dedicated $100 \%$ outdoor air system.

Ground source heat pumps.

${ }^{*}$ Climate-dependent EEM 


\section{Energy Use Intensities by End Use}

NREL used EnergyPlus software to evaluate whether the Kohl's $55,000 \mathrm{ft}^{2}$ prototype design was likely to hit $50 \%$ savings versus ASHRAE 90.1-2004 and to estimate additional savings that might be provided by technologies not currently in the prototype design to see how far Kohl's could stretch its savings in the future.

The Kohl's design team maintains eQuest (DOE-2) energy models of its new construction prototype designs for multiple climate zones and of the corresponding ASHRAE 90.1-2004 Appendix $\mathrm{G}$ baseline models. These models are used to evaluate the energy performance of new prototype designs for LEED ${ }^{\mathrm{TM}}$ certification and to understand the potential energy savings of new technologies. NREL used information from these models to build EnergyPlus versions of the code baseline and current prototype models and used these versions to evaluate additional technologies.

The energy use intensity (EUI), the annual energy consumption divided by the floor area, of the code baseline and current prototype models is shown in the graph at the bottom of the page. Modeled energy savings by end use are displayed in the tables on page 5 . The current prototype is referred to as the "final design" below because Kohl's chose not to modify the prototype based on the energy modeling results at the time of publication.

Additional EEMs that were analyzed included additional roof insulation, daylight harvesting with sales floor electrical light dimming, LED exterior lighting, interior lighting power density (LPD) reduction using LEDs on the sales floor, desiccant dehumidification, lower heating supply air temperature, evaporative cooling of RTU condensers, photovoltaic electricity generation, and ground source heat pumps. When analyzed individually in comparison to the code baseline, several EEMs had promising business cases (using typical industry equipment costs). However, when added to the already high performance current prototype, the payback was unacceptably long for all EEMs except desiccant dehumidification and decreased heating air supply temperature.

\section{Code Baseline}

The first model represented minimal compliance with the prescriptive specifications of ASHRAE 90.1-2004 and ASHRAE 62.1-2004 for ventilation. The Kohl's code baseline model using TMY3 meteorological data for Myrtle Beach, South Carolina had an annual EUI of $96 \mathrm{kBtu} / \mathrm{ft}^{2}$. The modeling parameters were taken from Appendix G of Standard 90.1-2004.

\section{Final Design}

The second simulation incorporated the EEMs in the new construction prototype design. This model had an annual EUI of $48 \mathrm{kBtu} / \mathrm{ft}^{2}$, an annual energy savings of $50 \%$ versus ASHRAE 90.1-2004. Savings were evenly split between cooling, lighting, and fan energy. The prototype design features high-EER $(>12)$ packaged HVAC rooftop units with variable speed supply fans, demand controlled ventilation, and staged heating and cooling. Kohl's has achieved a very low LPD of $0.7 \mathrm{~W} / \mathrm{ft}^{2}$ on its sales floor using high efficiency T-8 fixtures, less than half allowed by ASHRAE 90.1-2004.

\section{Comparing Estimated Energy Use Intensity of Code Baseline and Final Designs}

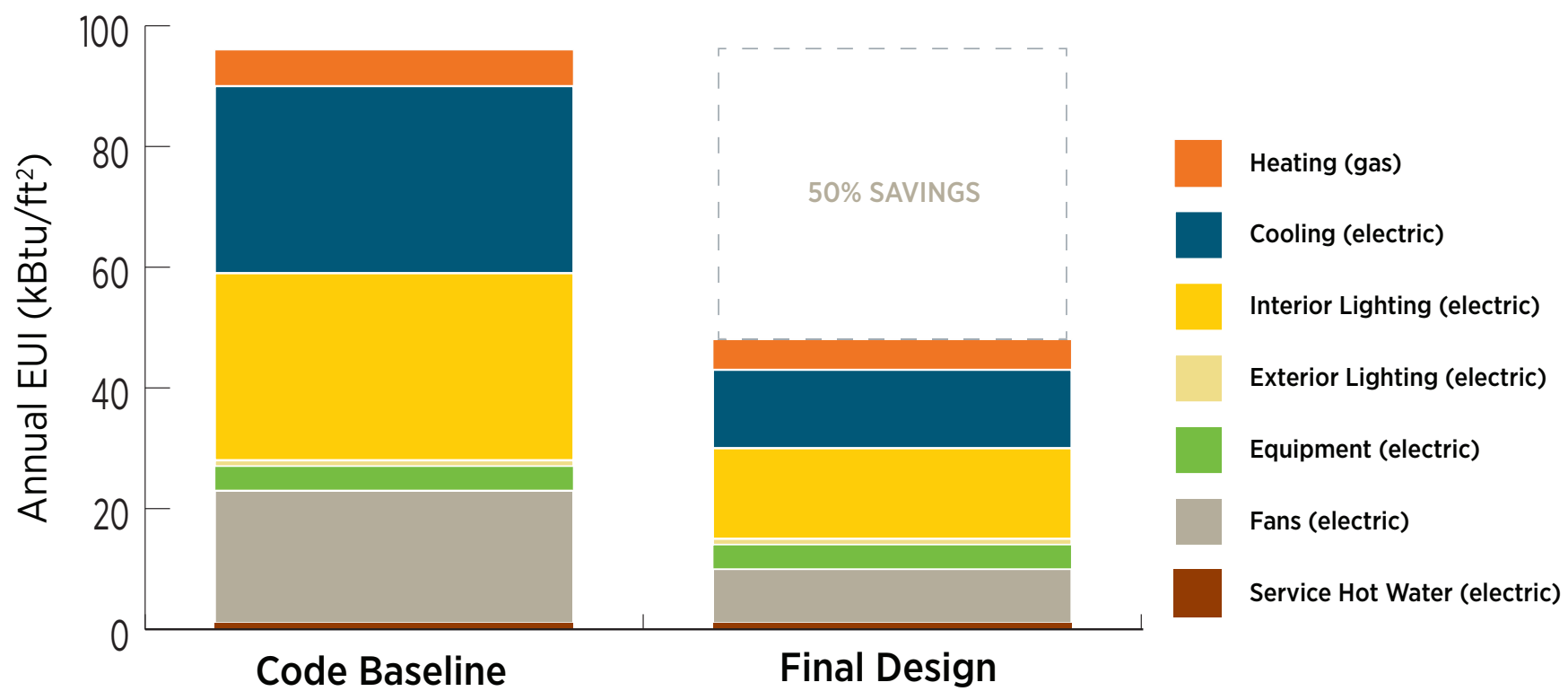


Estimated Annual Energy Use and Percentage Savings by End Use

\begin{tabular}{|l|c|c|c|}
\cline { 2 - 4 } \multicolumn{1}{c|}{} & $\begin{array}{c}\text { Code } \\
\text { Baseline }\end{array}$ & \multicolumn{2}{c|}{ Final Design } \\
\hline End Use Category & $\begin{array}{c}\text { Annual EUI } \\
\left(\mathrm{kBtu} / \mathrm{ft}^{2}\right)\end{array}$ & $\begin{array}{c}\text { Annual EUI } \\
\left(\mathrm{kBtu} / \mathrm{ft}^{2}\right)\end{array}$ & $\begin{array}{c}\text { Percent Savings } \\
\text { Versus Code Baseline }\end{array}$ \\
\hline Heating (gas) & 6 & 5 & 13 \\
\hline Cooling (electric) & 31 & 13 & 57 \\
\hline Interior Lighting (electric) & 31 & 15 & 50 \\
\hline Exterior Lighting (electric) & 1 & 1 & 0 \\
\hline Equipment (electric) & 4 & 9 & 0 \\
\hline Fans (electric) & 22 & 1 & 61 \\
\hline Hot Water (electric) & 1 & $\mathbf{4 8}$ & 0 \\
\hline Total & $\mathbf{9 6}$ & $\mathbf{5 0}$ \\
\hline
\end{tabular}

Expected Building Energy Savings From Implemented EEMs by End Use versus Code Baseline

\begin{tabular}{ll} 
Electricity End Use Category \\
\hline Cooling & $287,000 \mathrm{kWh} / \mathrm{yr}$ \\
\hline Interior Lighting & $246,000 \mathrm{kWh} / \mathrm{yr}$ \\
\hline Fans & $218,000 \mathrm{kWh} / \mathrm{yr}$ \\
\hline Electricity Total & $\mathbf{7 5 1 , 0 0 0 ~} \mathbf{k W h} / \mathbf{y r}$ \\
\hline
\end{tabular}

Natural Gas End Use Category

Heating 400 therms/yr

Natural Gas Total 400 therms/yr 


\section{Lessons Learned}

As part of the CBP work on Kohl's new store prototype, Kohl's and DOE learned several lessons that can help other companies achieve similar results, as described below.

\section{Variable frequency drives pay off quickly}

Using variable frequency drives (VFDs) on supply fans in RTUs, which allows fans to ramp down when not needed, has proven to be a company-wide cost and energy savings strategy for Kohl's. Variable-speed fans are now standard in new construction and replacement units and Kohl's has even instituted a program to retrofit existing RTUs with VFDs, which pays back in just a few years. More than 5,000 Kohl's RTUs have been retrofitted with VFDs to date. VFDs are standard on new stores. In warm and humid areas, variable-speed RTU fans have the added advantage of improving humidity control which can be a significant issue in areas that require a small degree of sensible cooling and a large amount of dehumidification yet rely on direct expansion cooling to handle both types of cooling.

\section{Embed institutional knowledge in energy models}

Maintaining energy models of a company's current prototype design became standard practice several years ago at Kohl's. Kohl's stands out in terms of its innovation process for energy efficiency, systematically exploring the potential energy savings from new technologies, then testing those that have high enough performance or low enough cost to make economic sense to add to the prototype.

\section{Forge close ties with engineers}

Unlike some large companies, Kohl's does not have an in-house engineering staff. However, it has worked closely over many years with the same engineering firm, building trust and efficient workflows. The engineering firm is also responsible for maintaining the energy models mentioned above. By maintaining a multidisciplinary design team that meets regularly, Kohl's was able to efficiently manage change in its prototype plans and specifications, ensuring that the concerns of all stakeholders were heard and addressed and that all team members aimed for the same goal.
"As a national retailer, we know that

one of the biggest ways to reduce our

environmental footprint is to carefully

manage our energy use."

-Kohl's Sustainability Website, www.koh/sgreen.com

\section{Formulate solutions for regions not individual projects}

The structure of CBP initially focused on the private sector partners specifying a particular project as "the" CBP project. This approach worked well with certain types of building owners; however, with several retail companies it failed to account for their decision-making processes. One advantage of maintaining prototype designs is that decisions about where to locate stores can be made quickly in response to shifts in the market. However, this need for flexibility also makes these companies hesitant to commit to a project in a particular location. Once this concern was better understood, the CBP team focused on more general solutions that could be employed no matter where the company decided to build.

\section{LEDs make sense in some applications}

LED fixtures are beginning to appear more often in retail settings, both in the parking lot and on the sales floor as spot lighting. However, for general sales floor lighting Kohl's has driven the energy consumption of its T-8 fluorescent lighting down to the point that it is difficult to justify investing in LED fixtures based solely on energy savings. However, Kohl's is still testing the appearance of its sales items under LED fixtures and assessing other non-energy benefits of LEDs such as their long lifetime relative to fluorescents.
Prepared by the National Renewable Energy Laboratory (NREL), a national laboratory of the U.S. Department of Energy, Office of Energy Efficiency and Renewable Energy. NREL is operated by the Alliance for Sustainable Energy, LLC. 